\title{
Develop of Initial depth velocity model improvement from well logs information: 2D Viking Graben data set application
}

\author{
Jaime Collazos, Francisco Oliveira, J. J. S. de Figueiredo and Lucas Freitas, Federal University of Para \& INCT-GP
}

Copyright 2014, SBGf - Sociedade Brasileira de Geofísica

Este texto foi preparado para a apresentação no VI Simpósio Brasileiro de Geofísica, Porto Alegre, 14 a 16 de outubro de 2014. Seu conteúdo foi revisado pelo Comite Técnico do VI SimBGf, mas não necessariamente representa a opinião da SBGf ou de seus associados. É proibida a reprodução total ou parcial deste material para propósitos comerciais sem prévia autorização da SBGt.

\begin{abstract}
The initial velocity model plays an important role in the process of model building for depth imaging. A more adequate initial model may reduce considerably the number of iterations in such a laborious process. In this work, we use a combination of seismic image and well log to enhance the velocity model inverted by DIX. We applied our approach to a data from Viking Graben, North Sea. The enhanced initial model not only aggregates geological features to DIX's solution but also reduces the its velocity deviation from the logs.
\end{abstract}

\section{Introduction}

Integrating well logs and seismic data is crucial when estimating subsurface properties. The process involves some stages such as: seismic image processing, wavelet creation, geologic interpretation, and manual corrections. In the present work a conventional processing was performed (Yilmaz and Lucas, 1986), then the wavelet was created, the reflection was resampled and the synthetic seismogram was created (White and Simm, 2003; Munoz and Hale, 2012). Picking of horizons was conducted (Hale, 2010) in the conventional depth migration image, this picks were made between layers or reflections with consistent information of well (horizons are among the reflections) to construct horizon surfaces to facilitate the interpolation of the velocity model.

On the next step of the process, a synthetic seismogram is obtained from the convolution between the reflectivity function and the wavelet Ricker. This synthetic seismogram is compared with the seismic trace of the conventional post stack depth migration (PSDM) and with the new migrated section generated from the velocity model developed with well log information and then the correlation between these seismic traces is then evaluated.

\section{Methodology}

The data used in this work belongs to North Sea Basin, Viking Graben. This well log information is acquired from two wells located in a seismic line. The seismic data is made from 1001 shots point, spread of 120 channels, with a rate sample of $4 \mathrm{~ms}$ and time recording of $6 \mathrm{~s}$. The source and the receiver intervals are of $25 \mathrm{~m}$. The minimum and maximum offset are $262 \mathrm{~m}$ and $3237 \mathrm{~m}$ respectively. Figure 3 shows the depth migration, with a window of $1000 \mathrm{~m}$ to $3000 \mathrm{~m}$ depth and 700 to $1900 \mathrm{CMP}$.

We worked with two logs from wells, located on CMP 808 and CMP 1572 (Madiba and McMechan, 2003), Figure 1 and figure 2 show the $A$ and $B$ well data, Figure 3 shows the location of the two wells (blue line) in the seismic line.

The compressional velocity $\left(v_{\mathrm{p}}\right)$, the depth information from well log and the information of density $(\rho)$ were used to generate the synthetic seismogram, this synthetic seismic trace will be the reference trace. The information about the density for the profile located in CMP 1572 is insufficient, therefore we estimated the density of the second well from the velocity profile, using Equation 1 ( Gardner et al, 1974).

$$
\rho=0.25 * v_{p}^{0.31}
$$

where $v_{\mathrm{p}}$ is in $\mathrm{m} / \mathrm{s}$ and $\rho$ is in $\mathrm{g} / \mathrm{cm}^{3}$.

\section{Conventional Seismic Processing (PSDM)}

To perform the conventional processing we used the software PROMAX and applied: trace muting, band-pass filter (6-12-50-70Hz), Ormsby filter, spherical divergence correction, predictive deconvolution with $320 \mathrm{~ms}$ operator length and a $20 \mathrm{~ms}$ prediction operator. The velocity analysis was made at each $50 \mathrm{CMP}$ with semblance. The Kirchhoff time migration was performed with an aperture ratio of $5000 \mathrm{~m}$, and the conversion to $v_{r m s}$ velocity generated with DIX equation (Dix, 1955).

\section{Construction of Velocity functions from Well Log Data.}

We created a new velocity model using information from well data and PSDM. The idea is to construct a new velocity model using the interval velocity from only two wells profile. To do so, we needed to pick some points from the middle of the layers of the PSDM image and then fill this points with an average velocity obtained from some layers of the well next to the chosen horizons. With this, we can perform an interpolation between the two wells using the data of the velocity profiles combined with the points chosen between the wells to generate the new velocity model. Then, we can perform a time and depth migration using the new velocity model. Figure 4 shows a flowchart of the applied methodology. 


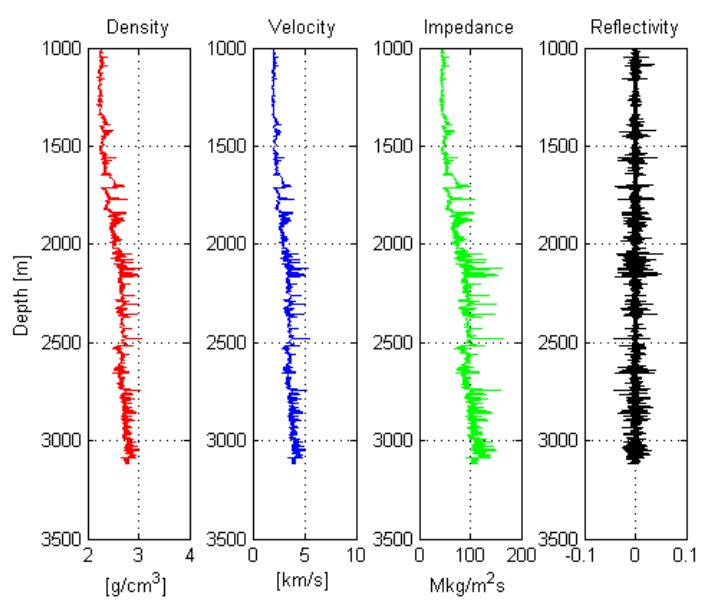

Figure 1: Information from well A, (a) Density $\left[\mathrm{g} / \mathrm{cm}^{3}\right]$, (b) Velocity [km/s], (c) Impedance [Mkg/m $\left.{ }^{2} \mathrm{~s}\right]$, (d) Reflectivity.
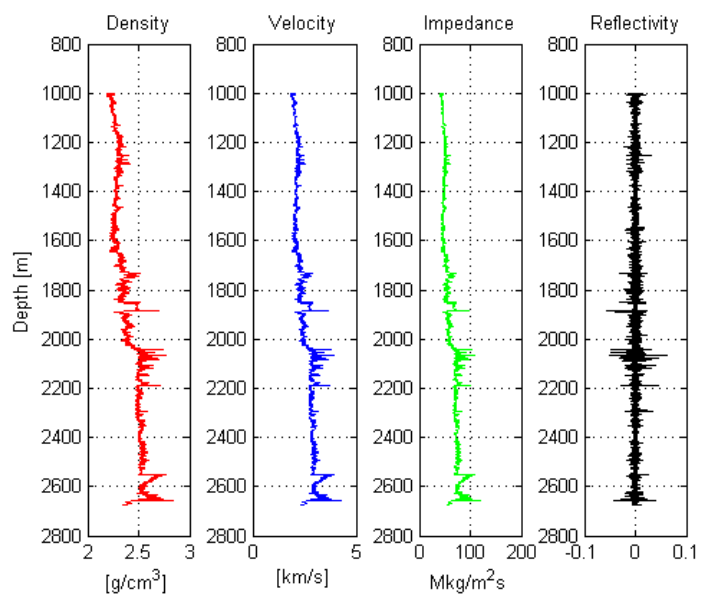

Figure 2: Information from well $B$, (a) Density $\left[\mathrm{g} / \mathrm{cm}^{3}\right]$, (b) Velocity [km/s], (c) Impedance [Mkg/m² $\mathrm{s}$, (d) Reflectivity.

\section{Picking Middle layers}

With the conventional processing, we had a PSDM image, with this data we can identify different layers, so if each layer has a different average velocity, we can use the velocity well information to make an average of each layer. To do so, we first did picks in the middle of each layer at each $50 \mathrm{CMP}$. In this step it is important to pick the same CMP on each layer, because we want to construct velocities functions to be used whit software PROMAX Figure 5 shows the picks at each 50 CDP.

\section{Assigning Velocity Values on Picks}

Using the PSDM we are able to choose the beginning and the end of each layer, according to the location of the well, so we can estimate the average velocity with the well log.

These velocities values were then assigned for each pick made in the previous step. This row of points is used to generate a interpolated velocity model.

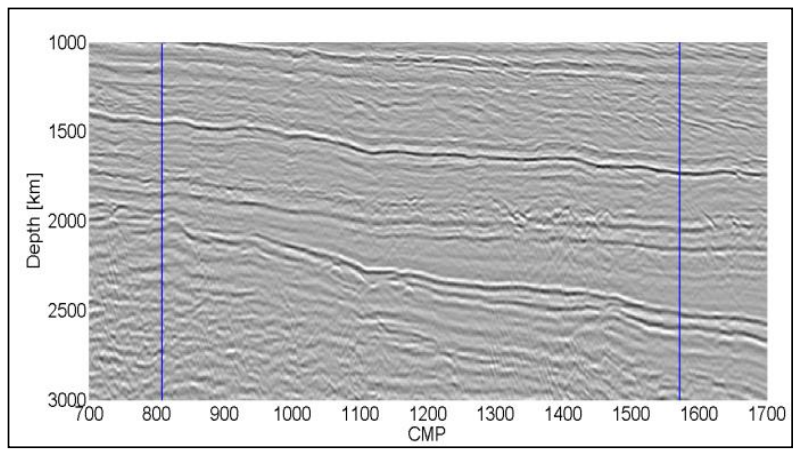

Figure 3: Conventional depth migration and location from well $A$ (CMP 808) and B (CMP 1572).

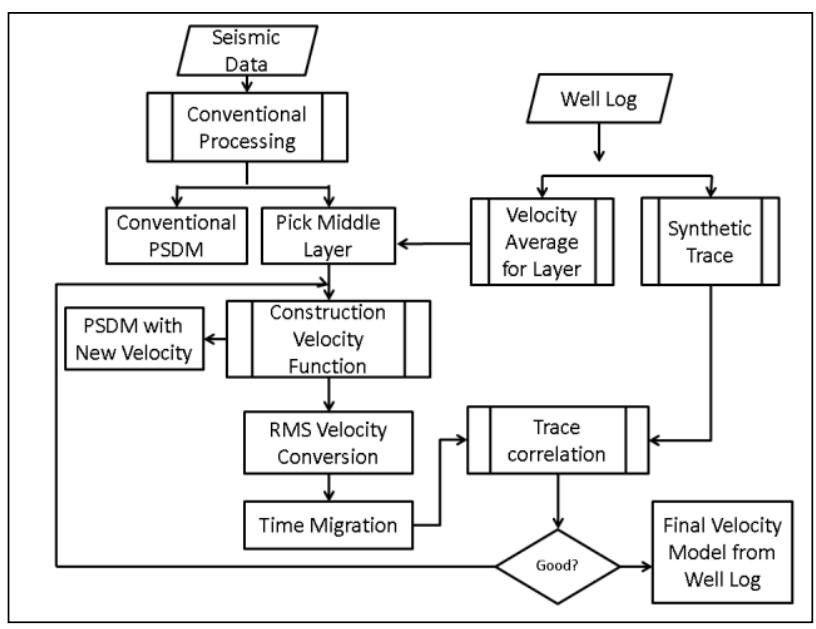

Figure 4: Flowchart of velocity model developed from well log.

The results obtained show that the new interpolated velocity model (velocity with well tie) in depth domain is more detailed when compared to the conventional velocity model (see Figures $6 \mathrm{a}$ and $6 \mathrm{~b}$ ) aggregating geological features to DIX's solution. The same conclusion can be taken from Figures $6 \mathrm{c}$ and $6 \mathrm{~d}$ of the velocity models in depth domain. The following steps are to perform a time and depth migration with the new velocity model and then evaluate this step by comparing the synthetic seismic trace generated from well with the seismic trace generated by the new velocity model interpolated. The measure of correlation will determine if the features are set.

\section{Synthetic seismogram}

A well with a velocity and density log is required to generate a synthetic seismogram. We used the well located at CMP 808 and CMP 1572, which have a Pwave velocity log and a density log.

The velocity $\log v(z)$ and the density $\log \rho(z)$ are uniformly sampled functions of depth for $z=z_{0}, z_{0}+$ $\Delta z, \ldots, z_{0}+\left(N_{z}-1\right) \Delta z$. They are used to construct the reflectivity given by 
$r(z)=\frac{v(z+\Delta z) \rho(z-\Delta z)-v(z) \rho(z)}{v(z+\Delta z) \rho(z-\Delta z)+v(z) \rho(z)}$.

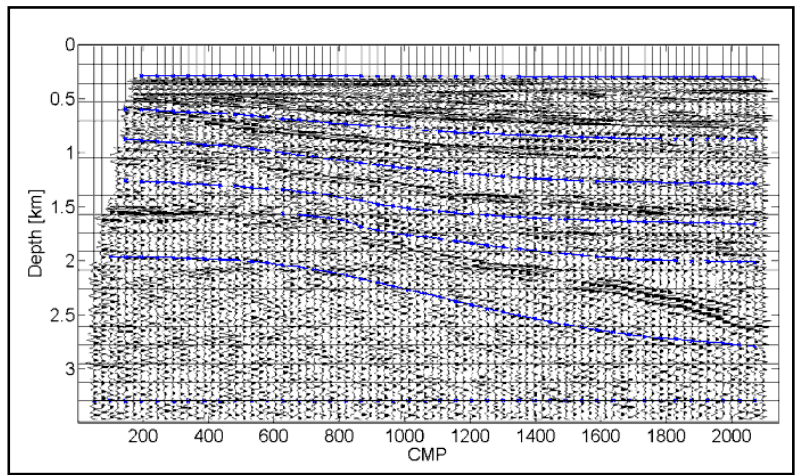

Figure 5: Picks at each $50 \mathrm{CMP}$ in middle layer.

(a)

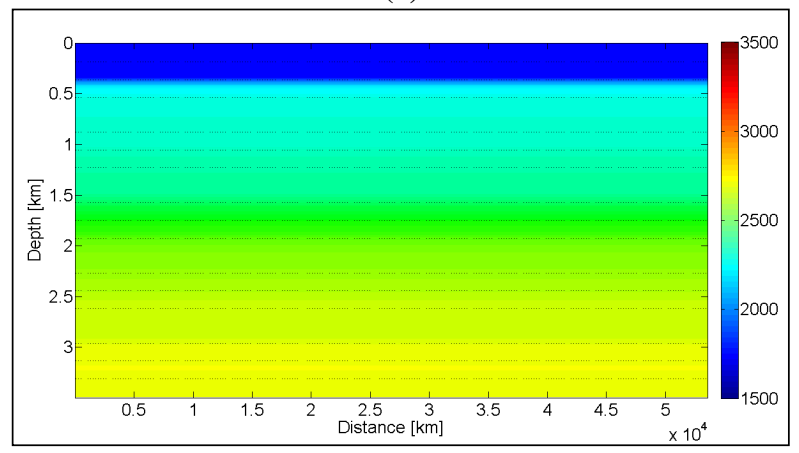

(b)

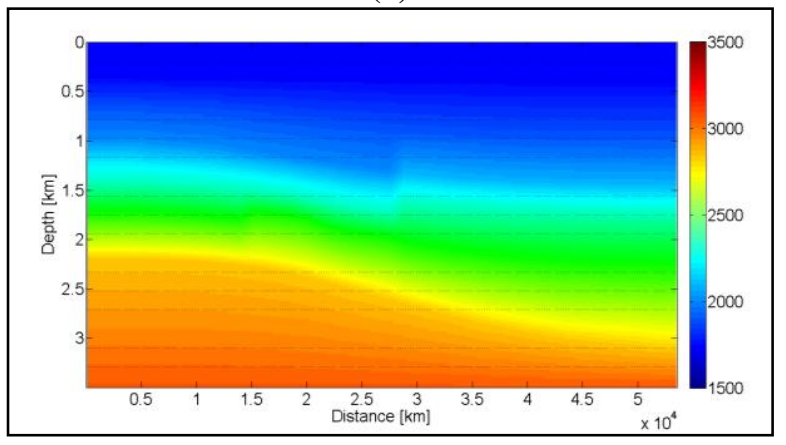

(c)

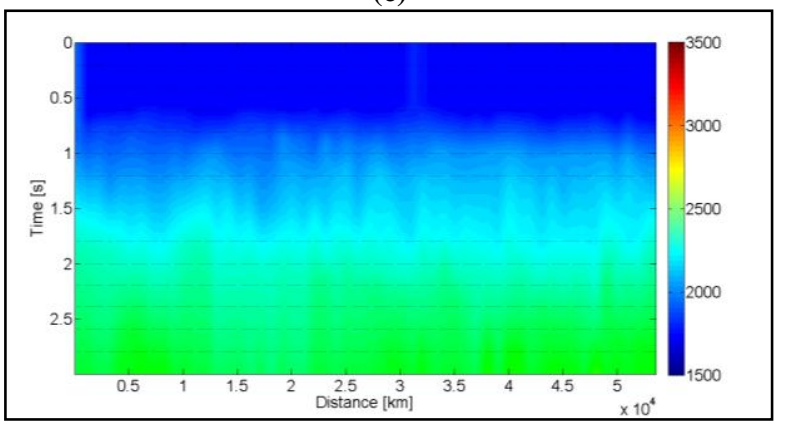

(d)

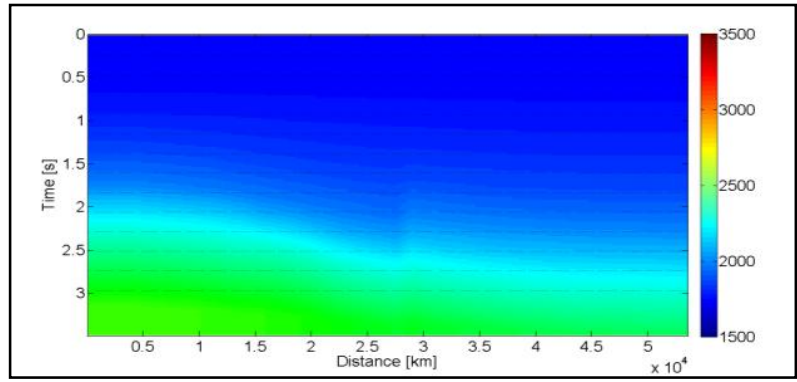

Figure 6: (a) Conventional depth velocity model, (b) depth velocity model using well tie , (c) RMS time velocity PSDM and (d) RMS time velocity from well log. The velocity model with well tie in depth and in time shows more details with aggregates geological features.

The synthetic seismic trace (Figure 8 and 9) is sampled with $\Delta \mathrm{t}=4 \mathrm{~ms}$ and we assume a constant wavelet with a peak frequency of $20 \mathrm{~Hz}$ (Figure 7). We combined a wavelet with the reflectivity (Figures, 8 and 9 ) to generate two synthetic seismograms (Connolly, 1999; Munoz and Dale, 2012), depicted in Figures 8 and 9.

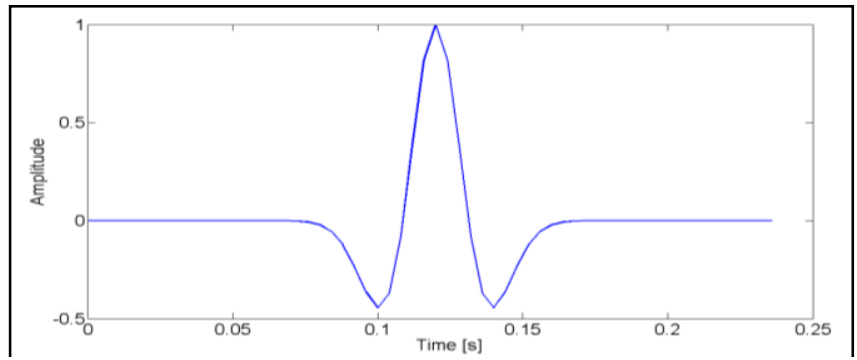

Figure 7: Synthetic seismogram with a peak frequency of $20 \mathrm{~Hz}$.

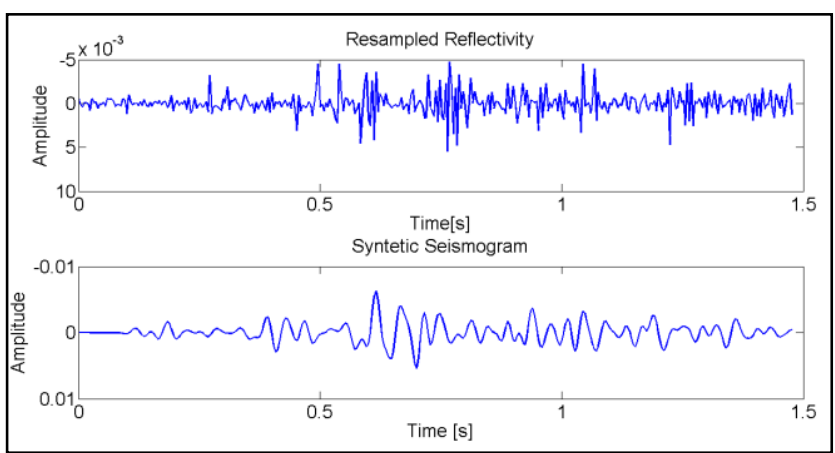

Figure 8: Well $A$, resampled reflectivity and synthetic seismogram.

In Figure 10a and 10b we can see the Kirchhoff time migration of seismic line using the conventional velocity model (PSDM) and the interpolated velocity model with well tie. We can observe in this seismic section a better continuity and definition of deeper events in Figure 10b and consequently a better resolution of this events.

\section{Correlation with Well log and Seismic Data}

To check if our method to construct a new velocity model enhances the velocity for semblance, we made a 
correlation between synthetic traces obtained from the conventional processing (PSDM) and well tie from CMP

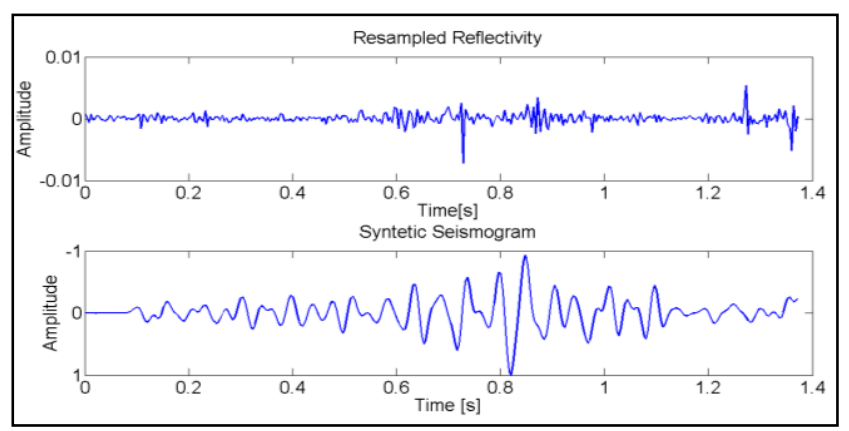

Figure 9: Well B, resampled reflectivity and synthetic seismogram.

808 and 1572. For well A (CMP 808) the correlation improved considerably, with values from 0.07 of conventional processing to 0.35 for well tie. For well B (CMP 1572), the correlation with traces of conventional processing is good (0.23), but in the correlation obtained with well tie velocity model, we found a correlation of 0.30. In other word, the conventional processing performed close to well $A$ generated a very different velocity model when compared to real velocity (well log). This happens because this area has little reflectors. On the other hand, the conventional processing is close to well B closest to the real velocity. This velocity was improved with well tie, where we found better results. Figures 11 and 12 show the plot of synthetic and seismic correlation trace.

\section{Depth Migration}

To know the true position of reflectors is the most important in depth migration, though is necessary to have a good velocity model. With well tie processing we get a depth velocity model improved when compared with PSDM velocity model and thus an processing image with better definition and continuity of deeper events. The figure 13 and 14, show a window of seismic data closes well sonic information.

We can see that depth migration with velocity model well tie located the reflectors in the same position of well sonic information, we used a post-stack kirchhoff depth migration.

The well tie velocity model can be used to migrate any data set so these are been constructed with a different velocity model, because depth migration only going to relocate the events in depth without lose the continuity.

This velocity model is generated in just a few minutes, the results for well tie are better than conventional velocity models. This model was interpolated using a process of pickings of horizons to fill some points between the two wells.

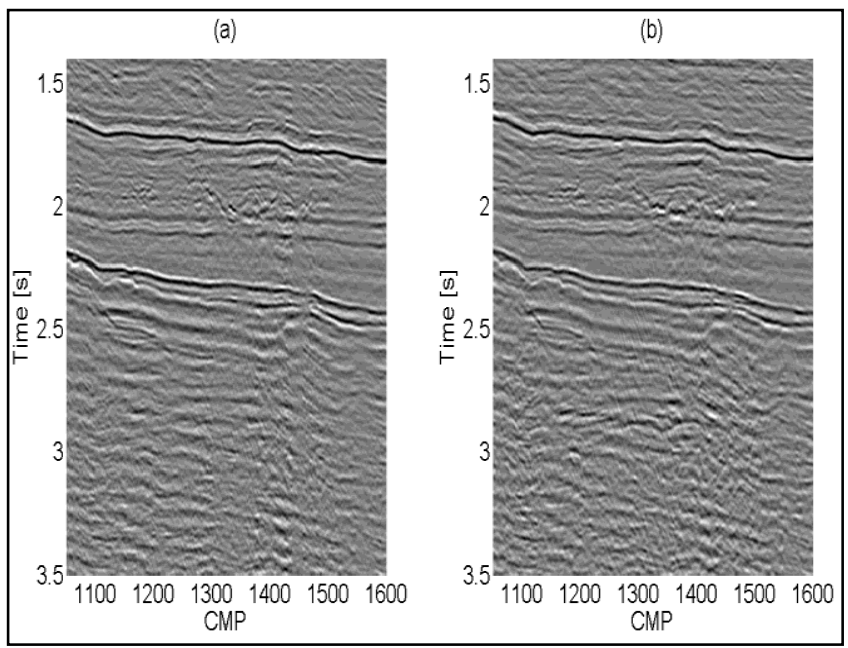

Figure 10: Time migration, (a) conventional processing and (b) well tie processing. We can observe a better definition and continuity of deeper events in Figure b.

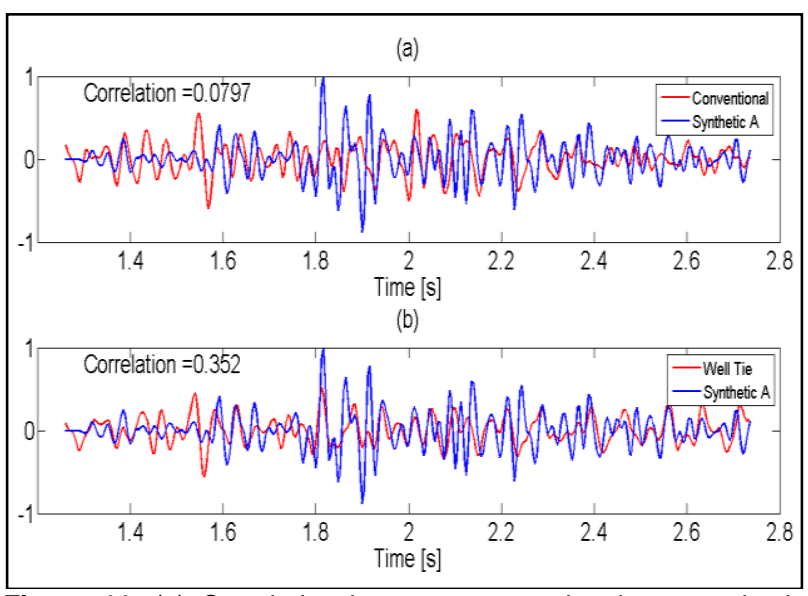

Figure 11: (a) Correlation between conventional trace seismic and synthetic trace of well A (CMP 808), (b) correlation between well tie seismic trace and synthetic trace well A (CMP 808). In Figure $b$ the correlation is better, resulting in a good adjust between the seismic traces.

\section{Conclusions}

Determining a more accurate velocity model is essential for a good sequence of the seismic processing. In this work an new velocity model is obtained from association between the information of the conventional seismic processing (PSDM) and two wells located in the seismic line at CMP 808 and 1572.

This new velocity model was then used in time and depth migration, and the result was a seismic signal with better quality in comparison to the conventional process in terms of resolution and continuity of events.

When we used depth velocity model in depth migration, we found that the reflectors or layers had better correlation with the well data (well A and well B), in other 


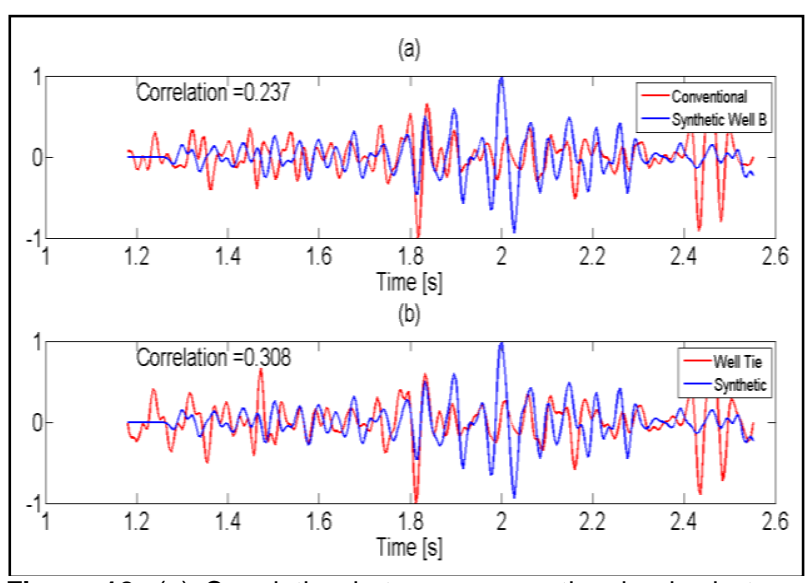

Figure 12: (a) Correlation between conventional seismic trace and synthetic trace well B (CMP 1572), (b) correlation between well tie seismic trace and synthetic trace well B (CMP 1572). In Figure $b$ the correlation is slightly better than the Figure a, resulting in a improved adjust between the seismic traces.

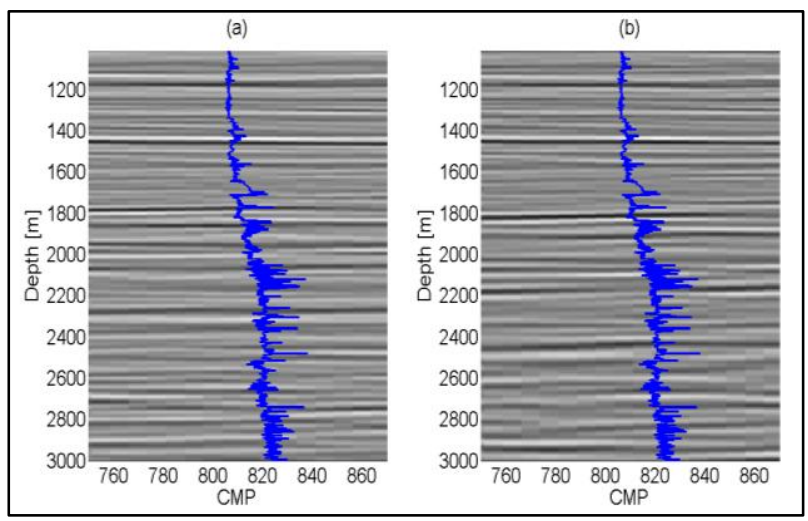

Figure 13: Depth migration and well A (sonic, blue line), (a) Conventional processing, (b) well tie processing.

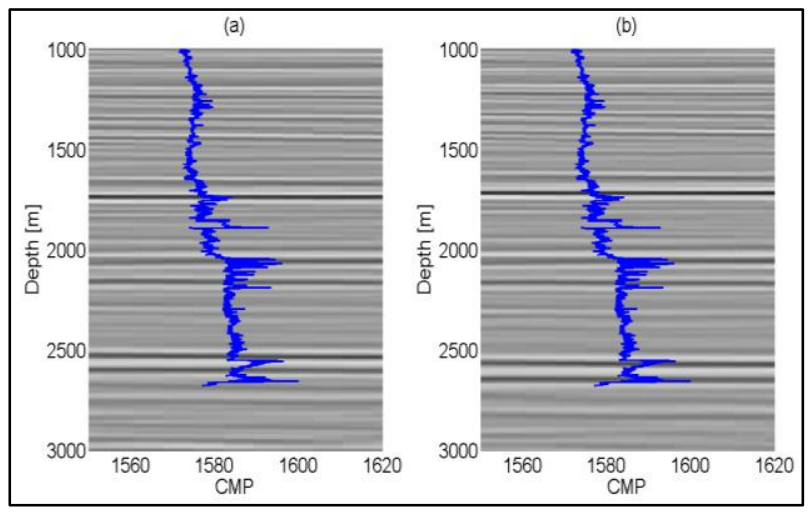

Figure 14: Depth migration and well B (sonic, blue line), (a) Conventional processing, (b) well tie processing. In well tie processing the sonic profile matches with the processing image in deepest events.

words, we located the reflectors in the true position. This work doesn't aim to replace the conventional processing, it only aims to show one more step in seismic processing, where the seismic data and well log are used to enhance a better resolution on time and depth migration and a good repositioning of the reflectors.

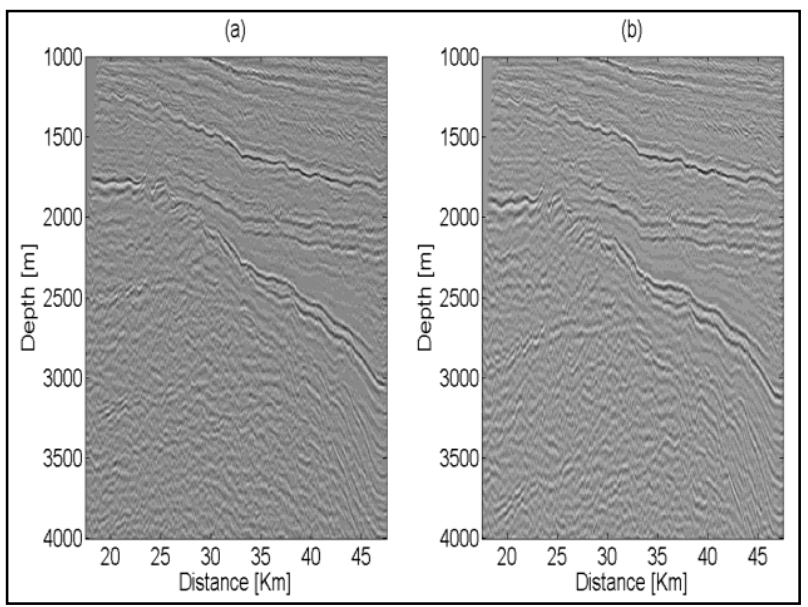

Figure 15: Depth migration, (a) conventional processing and (b) well Tie processing. In Figure $b$ the processing repositioned the deepest reflectors to the same position of the sonic profile.

With this methodology, it is possible to construct a good velocity model in time and depth domain, using the conventional processing associated with well log information. The further goal is to improve the method, applying it on 3D seismic data.

\section{Acknowledgments}

The authors would like to thank the ExxonMobil for providing the well log data set and the ProMAX Software. This work was kindly supported by the Brazilian agencies CAPES, INCT-GP, and CNPq, as well as Petrobras.

\section{Bibliography}

Connolly, P., 1999. Elastic impedance: The Leading Edge, 438-452.

Dix, C. H., 1955. Seismic velocities from surface measurements: Geophysics, 20, 68- 86.Gardner,

Gardner, G.H.F., Gardner, L.W., and Gregory, A.R., 1974. Formation velocity and density - the diagnostic basics for stratigraphic traps:Geophysics, 39, 770-780.

Madiba, G. B., and McMechan, G. A. , 2003. Processing, inversion, and interpretation of a $2 \mathrm{D}$ seismic data set from the North Viking Graben, North Sea, Geophysics, VOL. 68, NO, P. 837-848.

Hale, D., 2010. Image-guided 3D interpolation of borehole data .Center for Wave Phenomena, Colorado School of Mines.

Munoz, A., Hale, D., 2012. Automatically Tying Well Logs to Seismic Data, Center for Wave Phenomena Report 725.

White, R.E and Simm, R., 2003. Good Practice in well ties, First break, Vol 21, No 10, 75-83.

Yilmas, O., and Lucas, D., 1986. Prestack layer replacement: Geophysics, 51, no. 7, 1355-136. 